\title{
Bone Marrow Stem Cell Therapy (SCT) for Peripheral Arterial Disease (PAD): an Initial Experience
}

\section{Nick Ng Zhi Peng ${ }^{1 *}$, Tan Qing Ting ${ }^{2}$ and Benjamin Chua Soo Yeng ${ }^{3}$}

${ }^{1}$ Singhealth General Surgery (SHS), Singapore

${ }^{2}$ Department of Breast Surgery, $K K H$, Singapore

${ }^{3}$ Advanced Endovascular Surgery (Melbourne, Australia) Vascular Surgeon, Mt Elizabeth Novena Hospital, Mt Elizabeth Orchard Hospital, Mt Alvernia Hospital, Gleneagles Hospital, Parkway East Hospital, Farrer Park Hospital, Raffles Hospital, Singapore

\begin{abstract}
Introduction: $30 \%$ of patients with critical limb ischaemia (CLI) are not suitable for conventional treatment. Use of stem cell therapy (SCT) is relatively new. This study shares an initial experience using SCT in 4 patients.

Methods: Approval from Institutional Medical Board Ethics Committee was obtained prior to commencement and informed consent was sought. Patients included had extensive CLI history that was no longer amenable to standard treatment. Bone marrow aspiration from the iliac crest was carried out under regional anaesthesia. This was later centrifuged and injected intramuscularly and adjacent to affected vessels. Wound surveillance was then performed.

Results: SCT was well tolerated in all 4 patients and 2 had favourable results. None developed related complications. Patients 1 and 2 showed improvement of rest pain, claudication symptoms and healing of ulcers. Angiogenesis and neovascularization can be seen in follow up angiography for patient 1 . Wound healing was not noted in the other 2 patients, with both requiring amputations eventually.

Discussion: The experience while early has been invaluable. The varied response suggests that factors determining treatment success remained unknown. Likewise, most other trials have consisted of small uncontrolled patient series, with few randomized studies. Haemodialysis, diabetes mellitus and coronary arterial disease factors seemed to negatively affect angiogenesis. Severity of rest pain and number of repeated interventions, in particular bypass procedures, may negatively intervene with neo-capillary formation. SCT may eventually provide hope to patients and physicians. More research can help determine a specific group of patients that will benefit most.
\end{abstract}

Keywords: Neuropathy; Stem cells; Therapeutic angiogenesis; Endothelial progenitor

\section{Introduction}

Critical limb ischaemia (CLI) is the most severe form of peripheral arterial disease where there is inadequate blood flow to maintain metabolic requirements of the tissues at rest [1]. Treatment is often challenging, with surgical or endovascular revascularisation considered to be the gold standard. Up to $30 \%$ of patients however, are not suitable for treatment and require limb amputation, while $25 \%$ suffer mortality from the disease [2]. This is due to the high operative risks conferred by concomitant chronic co-morbidities such as ischemic heart disease, chronic renal impairment, as well as the often adverse extent of vasculopathy with diffuse involvement of multiple levels and distal stenosis. Locally, $8.9 \%$ of the population between 18 and 69 years are diabetic, and the risk of CLI is increased 4 fold in these patients [3]. CLI in diabetes preferentially involve infra-popliteal distal calf vessels with diffuse, multi-level distal stenosis compounding the difficulties faced during revascularization. Patients require repeated procedures due to a combination of premature advanced atherosclerosis, peripheral neuropathy, impaired cellular immunity and impaired wound healing. Up to $45 \%$ of all amputees are diabetic, and a diabetic patient with CLI is 10 times more likely to require an amputation despite new technology and innovation in revascularization [4]

\section{Bone Marrow Stem Cell Therapy (SCT) in clinical practice}

Embryonic and adult stem cells have the capacity to renew and generate differentiated cells. Embryonic stem cells are pluripotent, while adult stem cells are partially lineage committed giving rise to specialized cells of the germ layer. (i.e., they are multipotent rather than pluripotent). Bone marrow stem cells include progenitor cells such as the multipotent adult progenitor cells, mesenchymal and haematopoietic stem cells. Endothelial progenitor cells are adult haemangioblast-derived cells. In addition to having all functional properties of endothelial cells, they secrete paracrine mediators, interleukins, growth factors (angiopoietins Ang1 and Ang2, vascular endothelial growth factor (VEGF)) and chemokines to encourage migration of endothelial and support cells and the further proliferation and differentiation of the progenitor cells. Likewise, mesenchymal stem cells stimulate endothelial cell migration and vessel tube formation. They too release factors, migrate to injured sites, differentiate and secrete further trophic factors for paracrine signalling, activating endothelial cells [5]. SCT in the treatment of PAD is relatively new. In 1997, Asahara et al. identified a class of bone marrow-derived, circulating endothelial progenitor cells that contribute to angiogenesis in ischemic tissues [6]. Thereafter, the first clinical trial of cell therapy for PAD was performed by Tateishi-Yuyama et al. in 2002 known as the Therapeutic Angiogenesis using Cell Transplantation Study (TACT),

*Corresponding author: Peng NNZ, Singhealth General Surgery (SHS), 5 Changi Village Rd \#04-2025 Singapore 500005, Tel +65 91524617; E-mail: ngzp_87@hotmail.com

Received June 07, 2017; Accepted June 16, 2017; Published July 10, 2017

Citation: Peng NNZ, Ting TQ, Yeng BCS (2017) Bone Marrow Stem Cell Therapy (SCT) for Peripheral Arterial Disease (PAD): an Initial Experience. J Blood Lymph 7: 171. doi: 10.4172/2165-7831.1000171

Copyright: @ 2017 Peng NNZ, et al. This is an open-access article distributed under the terms of the Creative Commons Attribution License, which permits unrestricted use, distribution, and reproduction in any medium, provided the original author and source are credited. 
where bone marrow derived mononuclear cells were injected into the gastrocnemius muscle, and subsequent improvement in ankle-brachial index $(\mathrm{ABI})$, transcutaneous oxygen tension, pain-free walking time, and rest pain was documented [7]. Since then, several studies have reported variations of stem cells usage, including embryonic, adult and induced pluripotent stem cells, examining the efficacy and safety of cell therapy while obtaining varying results $[8,9]$. The procedure has also been generally well tolerated, with the most frequent adverse reaction being local pain or anaemia. In this study, an initial experience with 4 patients who underwent SCT as an alternative therapy when standard revascularisation was no longer an option for them is described. The aim of the study is to see if these patients can avoid amputation through improved wound healing brought about by angiogenesis and vascular collateral formation.

\section{Materials and Methodology}

Approval from the Institutional Medical Board Ethics Committee was obtained prior to commencement of this study. Informed consent was sought from all patients undergoing this treatment. Patients selected had no evidence of underlying malignancy, with life expectancy of more than 6 months, not pregnant and were without known haematological disease. All patients selected had an extensive CLI history, multiple revascularisation procedures, failed revascularisation therapy or recalcitrant, recurrent, persistent disease not amenable to treatment for reasons including high surgical risk, multi-level distal disease or both as summarized in Table 1 .

\section{SCT procedure}

Bone marrow aspiration from the iliac crest was carried out under regional anaesthesia in the operating theatre. The aspirate is then centrifuged with the Terumo SmartPRep2 system (Figures 1A-E) to allow concentration of Bone Marrow-Mononuclear cells (BM-MNC). This was then injected intramuscularly, adjacent to the affected vessels, $1 \mathrm{~mL}$ at $2 \mathrm{~cm}$ intervals under ultrasound guidance with the remaining around ulcers and wounds (peri-lesional). Wound surveillance was performed at both inpatient and outpatient settings post procedure.

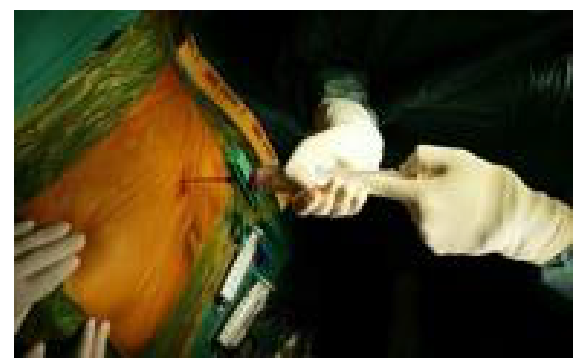

Figure 1A: Extraction of bone marrow from patient's ilium.

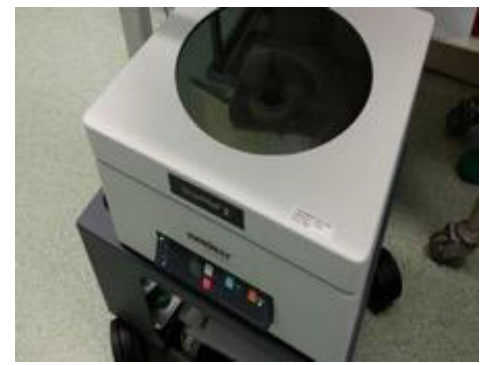

Figure 1B: Smart PRep2 centrifugation system.

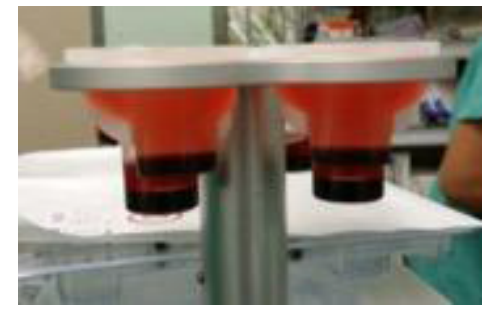

Figure 1C: Smart PRep2 centrifugation system

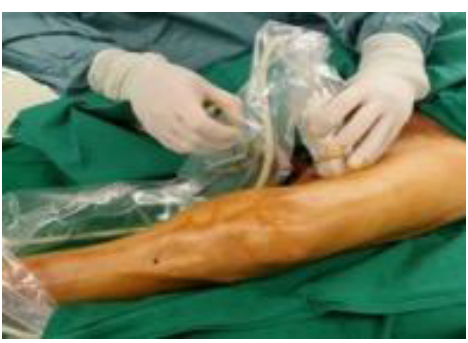

Figure 1D: Points of injection along vessel

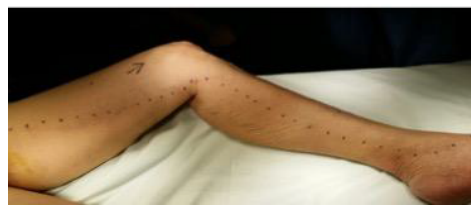

Figure 1E: Points of injection along vessel.

Clinical improvement in terms of reduced or resolution of symptoms was also noted (Figure 1).

\section{Results}

SCT was well tolerated in all 4 patients and patients 1 and 2 were discharged well. None of them developed direct SCT-related complications such as anaemia or severe injection site pain. Patients 1 and 2 benefitted from SCT with improvement of rest pain, claudication symptoms and healing of ulcers. We achieved the best results in Patient 1 who had excellent clinical improvement and was well enough to go abroad half a year after treatment. Angiogenesis and neovascularization can be seen in her follow up angiography 3 months post SCT. In patients 3 and 4, results of the treatment were not as encouraging. Wound healing was not noted in either. Patient 3, whose wound deteriorated further, underwent further multiple amputations to cope with the sepsis. Patient 4 was readmitted for exacerbation of cardiac failure brought about by NSTEMI about a month after treatment. Prior to his demise, the patient had returned to smoking, neglected foot care and declined further intervention or amputation. Table 2 summarizes the results of the patients undergoing SCT.

\section{Discussion}

The experience with injection of BM-MNCs for CLI in these 4 patients, while early, has been invaluable. Healing of ischemic ulcers demands an improvement in blood supply, good glycaemic control as well as tissue that is infection free. The treatment of CLI is often fraught with despair and the disease process is known to take a toll both physically and psychologically. Many patients develop fatalistic attitudes as they lose their limbs, give up on good glycaemic control 
Citation: Peng NNZ, Ting TQ, Yeng BCS (2017) Bone Marrow Stem Cell Therapy (SCT) for Peripheral Arterial Disease (PAD): an Initial Experience. J Blood Lymph 7: 171. doi: 10.4172/2165-7831.1000171

\begin{tabular}{|c|c|c|}
\hline \multicolumn{3}{|c|}{ Patient 1} \\
\hline \multicolumn{3}{|c|}{ 74/Chinese/Female } \\
\hline \multicolumn{3}{|c|}{ Non-smoker } \\
\hline \multicolumn{3}{|c|}{ Pre-morbidly ambulant, good social support } \\
\hline \multicolumn{3}{|c|}{ Past Medical History: Hypertension, hyperlipidaemia, ischaemic heart disease with triple vessel disease s/p CABG 2006} \\
\hline Signs/Symptoms & Investigations & Treatment/Interventions \\
\hline \multicolumn{3}{|c|}{ First Presentation } \\
\hline 61 years old & Right Duplex US and Angiography & Medical therapy with statins and anti-platelets \\
\hline Bilateral calf claudication & $\begin{array}{l}\text { Diffuse atherosclerotic changes in distal abdominal } \\
\text { aorta, R CIA, EIA, bilateral SFA, popliteal, ATA, PTA }\end{array}$ & Claudication exercises \\
\hline \multicolumn{3}{|l|}{ Intermittent rest pain } \\
\hline \multicolumn{3}{|c|}{13 Years Later } \\
\hline Further decreased claudication distance & Toe Pressures & Left LL Angioplasty \\
\hline Rest pain & Left- $0 \mathrm{mmHg}$, Right- $2 \mathrm{mmHg}$ & $\begin{array}{l}\text { Severe long segment stenosis and occlusion bilateral } \\
\text { CIA, EIA, SFA reconstituted at P2 level with run off via } \\
\text { PTA and peroneal artery }\end{array}$ \\
\hline \multirow{6}{*}{$\begin{array}{l}\text { Left mid shin and dorsal foot non-infected ulcers with } \\
\text { exposed tendons, absent pedal pulses }\end{array}$} & & Brisk flow to profunda via collaterals \\
\hline & US Duplex and Angiography (Figure 2) & \\
\hline & $\begin{array}{c}\text { Bilateral EIA, CFA, SFA severely calcified and } \\
\text { occluded to popliteal, peroneal and L DP occluded. } \\
<1 \mathrm{~mm} \text { trickle to R PTA }\end{array}$ & DEB to $L C I A$ and EIA performed \\
\hline & CT Peripheral Angiography & $\begin{array}{l}\text { Failed SFA plasty- with balloon rupture secondary to } \\
\text { calcified occlusion. }\end{array}$ \\
\hline & $\begin{array}{l}\text { Extensive atherosclerosis involving aorta, stenosis of } \\
\text { common, internal, external iliac arteries and CFA }\end{array}$ & \\
\hline & & Considered Aorto-illiac bypass \\
\hline \multicolumn{3}{|c|}{3 Months Later } \\
\hline \multirow{2}{*}{$\begin{array}{l}\text { Left lower limb cellulitis and distal ulcers with wet } \\
\text { gangrene and exposed mid-foot tendon }\end{array}$} & \multirow[t]{2}{*}{ No investigations done } & Declined amputations or surgical bypass for fear of risks \\
\hline & & Treated with IV antibiotics till ulcers stable \\
\hline \multicolumn{3}{|c|}{ Patient 2} \\
\hline \multicolumn{3}{|c|}{ 66/Chinese/Male } \\
\hline \multicolumn{3}{|c|}{ Non-smoker } \\
\hline \multicolumn{3}{|c|}{ Pre-morbidly wheelchair mobile, good social support } \\
\hline \multicolumn{3}{|c|}{$\begin{array}{l}\text { Past Medical History: Hypertension, hyperlipidaemia, diabetes mellitus, ischaemic heart disease with triple vessel disease s/p CABG }>10 \text { years ago, congestive cardiac } \\
\text { failure (EF } 27 \%) \text {, Left neck of femur fracture conservatively managed with straight leg traction }\end{array}$} \\
\hline Signs/Symptoms & Investigations & Treatment/Interventions \\
\hline \multicolumn{3}{|c|}{ First Presentation } \\
\hline 64 years old & CT Peripheral Angiography & \multirow[t]{5}{*}{ Right CFA end-arterectomy, EIA and CIA stenting } \\
\hline Rest Pain & $\begin{array}{l}\text { Diffuse atherosclerotic changes of aorta, iliac, } \\
\text { femoral, popliteal and trifurcation }\end{array}$ & \\
\hline Right anterior shin ulcer & & \\
\hline & Bilateral Lower Limb Angiography & \\
\hline & $\begin{array}{c}\text { Severe calcified atheromatous disease affecting } \\
\text { aorta, bilateral CIA, EIA, CFA, SFA, reconstituting at } \\
\text { popliteal via profunda collaterals }\end{array}$ & \\
\hline \multicolumn{3}{|c|}{ Immediate Post-operatively } \\
\hline Developed bilateral dusky toes & Repeat Angiography & $\begin{array}{c}\text { Repeat Angioplasty of Right EIA, stenting of Left } \\
\text { EIA, Right SFA }\end{array}$ \\
\hline $\begin{array}{l}\text { Dry gangrene of right big toe and pus involving tendon } \\
\text { sheaths }\end{array}$ & Narrowed profunda artery & Right BT Ray amputation and debridement \\
\hline \multicolumn{3}{|c|}{4 Months Later } \\
\hline Poor healing of Right BT amputation wound & & $\begin{array}{l}\text { Debridement of Right BT amputation site and heel } \\
\text { wound }\end{array}$ \\
\hline Dry gangrene with slough, heel ulcer with exposed bone & & Right LL angioplasty \\
\hline \multirow[t]{2}{*}{ Left heel ulcer with dry gangrene } & & Declined below knee amputation \\
\hline & & Left SFA stenting and PTA angioplasty \\
\hline \multicolumn{3}{|c|}{5 Months Later } \\
\hline Right heel bone and Left TA exposed & US Duplex & Bilateral wound debridement \\
\hline Increased rest pain & Bilateral in-stent stenosis & Bilateral LL Angioplasty \\
\hline & & Done mainly to stent and popliteal arteries \\
\hline
\end{tabular}


Citation: Peng NNZ, Ting TQ, Yeng BCS (2017) Bone Marrow Stem Cell Therapy (SCT) for Peripheral Arterial Disease (PAD): an Initial Experience. J Blood Lymph 7: 171. doi: 10.4172/2165-7831.1000171

Page 4 of 8

\begin{tabular}{|c|c|c|}
\hline \multicolumn{3}{|c|}{4 Months Later } \\
\hline Increased frequency of Right LL rest pain & US Duplex & Left LL angioplasty, EIA stent, CFA, popliteal plasty \\
\hline Left foot $4 \times 4 \mathrm{~cm}$ dry ulcer & Recurrent SFA in-stent stenosis & $\begin{array}{l}\text { Unable to tolerate } \mathrm{R} \mathrm{LL} \text { angioplasty in prone position, } \\
\text { rescheduled ATA plasty }\end{array}$ \\
\hline \multicolumn{3}{|l|}{ Right foot $8 \times 4 \mathrm{~cm}$ ulcer with dry gangrene } \\
\hline \multicolumn{3}{|c|}{5 Months Later } \\
\hline Increased rest pain & \multirow[t]{3}{*}{ No investigations done } & Left LL angioplasty with L Iliac stent plasty \\
\hline Stable ulcers, no gangrene & & (Simultaneous with PCl) \\
\hline $\begin{array}{l}\text { Developed CCF secondary to NSTEMI, underwent } \\
\text { Coronary PCI }\end{array}$ & & \\
\hline \multicolumn{3}{|c|}{6 Months Later } \\
\hline Deterioration of bilateral foot ulcers & US Duplex & Bedside debridement (in view of recent NSTEMI) \\
\hline \multirow[t]{2}{*}{ Exposed bone with pus } & Severe calcification bilaterally & \\
\hline & - Right EIA stent only trickle of flow & Left BKA, Right foot wound debridement \\
\hline \multicolumn{3}{|c|}{6 Months Later } \\
\hline \multirow[t]{2}{*}{ Stable symptoms } & US Duplex & \multirow[t]{2}{*}{ Right LL angioplasty to EIA, SFA and ATA } \\
\hline & $\begin{array}{l}\text { Right SFA full length in stent stenosis and occlusion, } \\
\text { ATA, DP occluded }\end{array}$ & \\
\hline \multicolumn{3}{|c|}{4 Months Later } \\
\hline Worsening Right foot ulcers & US Duplex & $\begin{array}{l}\text { Right LL angioplasty to Right SFA in-stent stenosis, } \\
\text { DEB applied }\end{array}$ \\
\hline $2^{\text {nd }}$ toe gangrene & Persistent SFA in-stent stenosis & Failed ATA angioplasty \\
\hline \multicolumn{3}{|c|}{ Patient 3} \\
\hline \multicolumn{3}{|c|}{ 81/Malay/Female } \\
\hline \multicolumn{3}{|c|}{ Non-smoker } \\
\hline \multicolumn{3}{|c|}{ Pre-morbidly wheelchair mobile, good social support } \\
\hline \multicolumn{3}{|c|}{$\begin{array}{l}\text { Past Medical History: Hypertension, hyperlipidaemia, End stage renal failure on haemodialysis, ischaemic heart disease with NSTEMI, Left knee fracture managed } \\
\text { conservatively }\end{array}$} \\
\hline Signs/Symptoms & Investigations & Treatment/Interventions \\
\hline \multicolumn{3}{|c|}{ First Presentation } \\
\hline 78 years old & \multirow[t]{2}{*}{ Declined investigations } & Medical therapy with anti- platelet and statins \\
\hline Cold toes, rest pain, no tissue loss & & Declined vascular imaging or intervention \\
\hline \multicolumn{3}{|c|}{5 Months Later } \\
\hline Wet gangrene of Right lateral foot $4^{\text {th }}$ and $5^{\text {th }}$ toes & Angiography & Right $4^{\text {th }}$ and $5^{\text {th }}$ toe amputation \\
\hline Increased rest pain & Multifocal SFA stenosis and popliteal, PTA occluded. & \\
\hline Absent distal pulses & Collaterals seen. & Bilateral Angioplasty \\
\hline & & R SFA, popliteal, TP trunk and peroneal, \\
\hline & & L SFA, L popliteal artery plastied \\
\hline \multicolumn{3}{|c|}{2 years later } \\
\hline Wet gangrene of Right $3^{\text {rd }}$ toe & Angiography & Bilateral BT Amputation, Right $2^{\text {nd }}$ toe debridement \\
\hline Bilateral dry gangrene with small ulcers & $\begin{array}{l}\text { Bilateral SFA, popliteal, R TP trunk, proximal ATA, L } \\
\text { ATA, L PTA L DP multiple stenosis }\end{array}$ & Left $5^{\text {th }}$ MT debridement \\
\hline \multicolumn{3}{|c|}{ Patient 4} \\
\hline \multicolumn{3}{|c|}{ 81/Chinese/Female } \\
\hline \multicolumn{3}{|c|}{ Smoker } \\
\hline & Pre-morbidly wheelchair mobile, good social support & \\
\hline Past Medical History: Hypertension, hyperlipidaemia, & $\begin{array}{l}\text { iple vessel disease s/p CABG 1997, NSTEMI } 2014 \mathrm{~s} / \mathrm{p} \\
\text { atrial fibrillation on Warfarin }\end{array}$ & multiple PCls, congestive cardiac failure, paroxsysmal \\
\hline Signs/Symptoms & Investigations & Treatment/Interventions \\
\hline & First Presentation & \\
\hline 75 years old & R LL Angiography & Right LL Angioplasty \\
\hline Right leg rest pain and cold feet & $\begin{array}{l}\text { Sub-acute popliteal artery occlusion extending into } \\
\text { peroneal and PTA, reformed with collaterals }\end{array}$ & $\begin{array}{l}\text { Unable to cross into peroneal and PTA despite multiple } \\
\text { attempts }\end{array}$ \\
\hline Debilitating claudication distance & & $\begin{array}{l}\text { Covered stent placed across popliteal occlusion and } \\
\text { coronary stent placed into proximal PTA with single PTA } \\
\text { run off eventually. }\end{array}$ \\
\hline No tissue loss & & \\
\hline & & Thrombolysis to acute stent thrombosis \\
\hline & & $\begin{array}{l}\text { Check angiography POD } 2 \text { showed satisfactory } \\
\text { recanalization of SFA and popliteal artery }\end{array}$ \\
\hline POD 1: Acute stent thrombosis & & \\
\hline & 3 months later & \\
\hline
\end{tabular}


Citation: Peng NNZ, Ting TQ, Yeng BCS (2017) Bone Marrow Stem Cell Therapy (SCT) for Peripheral Arterial Disease (PAD): an Initial Experience. J Blood Lymph 7: 171. doi: 10.4172/2165-7831.1000171

Page 5 of 8

\begin{tabular}{|c|c|c|}
\hline Recurrent cold right leg & US Duplex & Right LL Angioplasty \\
\hline \multirow[t]{6}{*}{ Increased rest pain } & Recurrent subacute occlusion & PTA stent angioplasty with good results \\
\hline & & - Self-expanding Stent inserted in mid SFA \\
\hline & Angiography & \\
\hline & In stent thrombosis & \\
\hline & $\begin{array}{c}\text { Occlusion from mid-thigh SFA with slow distal flow } \\
\text { and no reconstitution of PTA }\end{array}$ & \\
\hline & Slow flow to DP & \\
\hline \multicolumn{3}{|c|}{6 years later } \\
\hline Right heel dry ulcer & US Duplex & $\begin{array}{l}\text { Angioplasty of popliteal artery stent and P2 region } \\
\text { and TP trunk and peroneal artery with DEB }\end{array}$ \\
\hline Right $3^{\text {rd }}$ toe dry gangrene & $\begin{array}{l}\text { Occluded popliteal artery stent with occluded PTA } \\
\text { and ATA, monophasic flow to foot }\end{array}$ & \\
\hline \multicolumn{3}{|l|}{ Increased rest pain } \\
\hline & Angiography & Offered bypass surgery- declined \\
\hline \multirow[t]{2}{*}{ Post angioplasty: Persistent cold heel and toe pain } & Complete popliteal artery in stent occlusion & \\
\hline & $\begin{array}{l}\text { TP trunk occluded into proximal peroneal artery, } \\
\text { occluded ATA and PTA }\end{array}$ & \\
\hline
\end{tabular}

ATA: Anterior Tibial Artery; BKA/AKA: Below Knee Amputation/Above Knee Amputation; BT: Big Toe; CABG: Coronary Artery Bypass Graft; CFA: Common Femoral Artery; CIA: Common lliac Artery; DEB: Drug Eluting Balloon; DP: Dorsalis Pedis; EF: Ejection Fraction; EIA: External Iliac Artery; L: Left; LL: Lower Limb; MI: Myocardial Infarction; PTA: Posterior Tibial Artery; R: Right; SFA: Superficial Femoral Artery; TA: Tendo-Achilles.

Table 1: Summary of patients' characteristics, co-morbidities, signs/symptoms, vascular investigations and Interventions Pre-SCT.

\begin{tabular}{|c|c|c|}
\hline Patient 1 & POD & Outcomes (Figures 3A-J, Figures 4A-D) \\
\hline \multirow{7}{*}{$\begin{array}{l}\text { Length of hospitalization } \\
\text { post SCT: } 5 \text { days }\end{array}$} & 15 & L shin and dorsal foot ulcers healing and granulating \\
\hline & 36 & L shin wound healed, foot defect smaller, healing \\
\hline & 78 & Continued healing seen \\
\hline & 89 & Left shin ulcer slight dehiscence $<1 \mathrm{~cm}$ \\
\hline & \multirow[t]{2}{*}{91} & Angiogram performed: \\
\hline & & $\begin{array}{l}\text { Patent CIA up to CFA, occlusions seen along SFA with neovascularization seen and multiple collaterals at adductor canal. } \\
\text { PTA reconstituted by collaterals, dorsal foot perfused by PTA }\end{array}$ \\
\hline & 6 months & Completely healed ulcers, able to travel abroad for holiday with no rest pain or significant claudication \\
\hline Patient 2 & POD & Outcomes (Figures $5 \mathrm{~A}-\mathrm{C}$ ) \\
\hline \multirow{4}{*}{$\begin{array}{l}\text { Length of hospitalization } \\
\text { post SCT: } 3 \text { days }\end{array}$} & 34 & Granulation tissue seen over dorsal foot wound \\
\hline & 74 & Further reduction in wound size and granulation \\
\hline & 109 & Healing of dorsal foot wound \\
\hline & 8 months & Wound size less than $1 \mathrm{~cm}$, No complains of rest pain \\
\hline Patient 3 & POD & Outcomes \\
\hline \multirow{5}{*}{$\begin{array}{l}\text { Length of hospitalization } \\
\text { post SCT: NA }\end{array}$} & 16 & No improvement of foot ulcers. Developed purulent discharge \\
\hline & 26 & Further deterioration requiring bilateral forefoot amputation and right heel debridement \\
\hline & 51 & Forefoot stump infection. Underwent R AKA and L forefoot wound debridement \\
\hline & 75 & $\begin{array}{l}\text { AKA stump dehiscence secondary to infection with purulent discharge and poorly felt femoral artery pulses, Underwent } \\
\text { stump revision and debridement }\end{array}$ \\
\hline & 4 months & Developed altered mental status secondary to sepsis, requested terminal discharge to Nursing Home, no follow up since \\
\hline Patient 4 & POD & Outcomes \\
\hline \multirow{6}{*}{$\begin{array}{l}\text { Length of hospitalization } \\
\text { post SCT: } 5 \text { days }\end{array}$} & \multirow[t]{3}{*}{8} & Readmitted for CCF sec to NSTEMI, stable right $3^{\text {rd }}$ toe and heel gangrene, no infection, persistent rest pain \\
\hline & & New R BT wound from accidental trauma at home \\
\hline & & Developed hospital acquired pneumonia with brief altered mental status secondary to sepsis \\
\hline & 17 & Increasing right foot duskiness and progression of gangrene \\
\hline & 25 & Restarted smoking, further increase in rest pain. Developed R BT wet gangrene, declined amputation \\
\hline & 47 & Passed on from NSTEMI with cardiac failure contributed by pneumonia and critical limb ischaemia \\
\hline
\end{tabular}

Table 2: Summary of SCT and patient outcomes.

or return to smoking as with patient 4 . Improvement in quality of life as seen in patients 1 and 2 can only take place with both ulcer healing and reduction of symptoms like rest pain and claudication. The varied response in the 4 patients suggests that while SCT can work, either the factors which influence its efficacy or the proper patient selection has not been truly determined. The exact science behind or conditions required to promote neovascularization demonstrated in the angiogram of
Patient 1 (see Photos) is not fully understood. SCT as a new therapeutic option have generally been offered only to end-stage PAD patients with CLI without other therapeutic options. Most clinical trials of cell therapy for PAD have consisted of uncontrolled patient series, with few randomized, properly controlled studies. Sample sizes have been small, with most studies enrolling fewer than 50 patients. The therapeutic product for nearly all of the trials has been bone marrow-derived 
Citation: Peng NNZ, Ting TQ, Yeng BCS (2017) Bone Marrow Stem Cell Therapy (SCT) for Peripheral Arterial Disease (PAD): an Initial Experience. J Blood Lymph 7: 171. doi: 10.4172/2165-7831.1000171

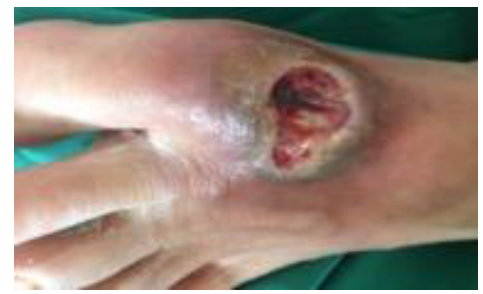

Figure 2A: Patient 1 PRE SCT Left dorsal foot ulcer.

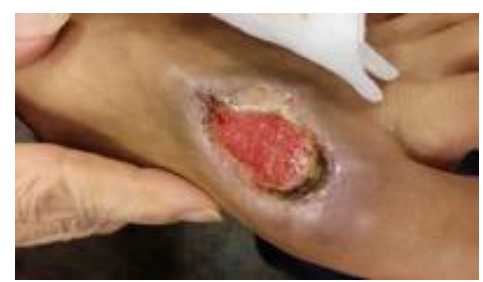

Figure 2B: Patient 11 month post SCT Left dorsal foot ulcer.

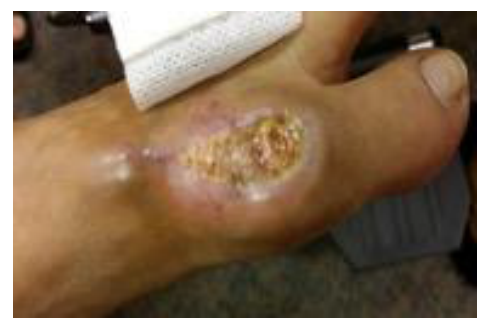

Figure 2C: Patient 14 months post SCT Left dorsal foot ulcer.

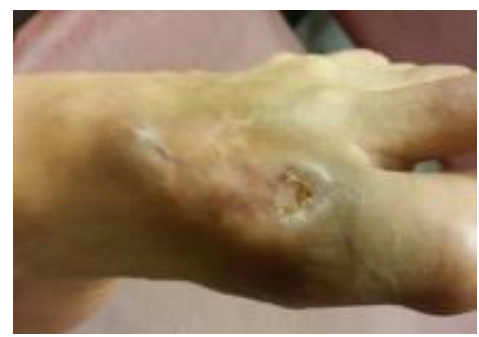

Figure 2D: Patient 16 months POST SCT Left dorsal foot ulcer.

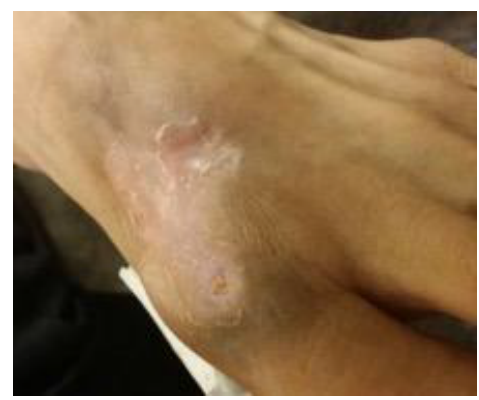

Figure 2E: Patient 17 months post SCT Left dorsal foot ulcer.

mononuclear cells and/or peripheral blood-derived mononuclear cells harvested with or without granulocyte colony-stimulating factor mobilization. Cells were delivered by direct intramuscular injection at multiple sites of the affected limb or by intra-arterial injection via

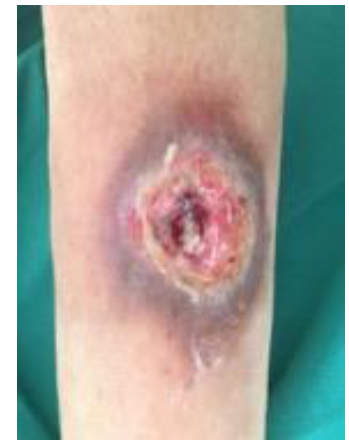

Figure 2F: Patient 1 PRE SCT Left shin ulcer.

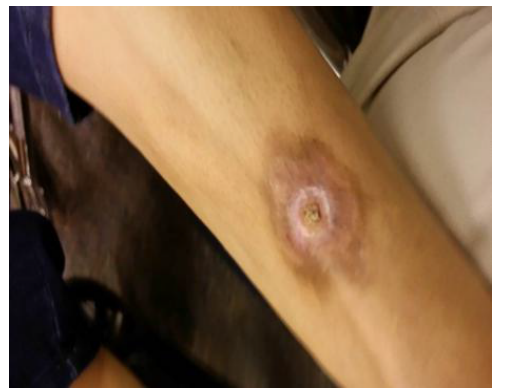

Figure 2G: Patient 1 month POST SCT Left shin ulcer.

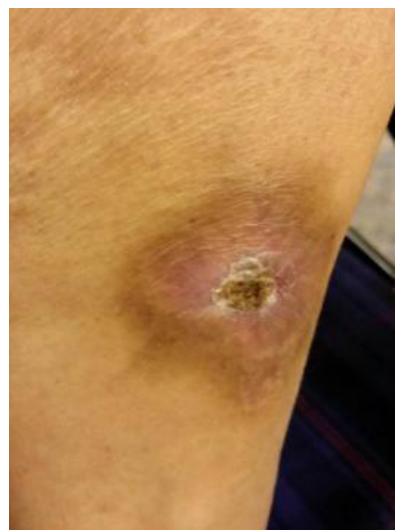

Figure 2H: Patient 14 months POST SCT Left shin ulcer

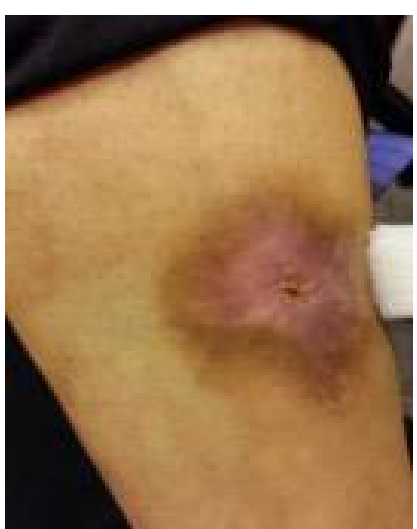

Figure 2I: Patient 16 months post SCT Left shin ulcer. 
Citation: Peng NNZ, Ting TQ, Yeng BCS (2017) Bone Marrow Stem Cell Therapy (SCT) for Peripheral Arterial Disease (PAD): an Initial Experience. J Blood Lymph 7: 171. doi: 10.4172/2165-7831.1000171

the femoral artery. Reported endpoints of these studies have included $\mathrm{ABI}$, transcutaneous oxygen tension, and angiography examined at baseline and following cell therapy, with an average follow-up period of approximately 6 months to 1 year. Subjective outcomes have also been reported, including patient-perceived rest pain and pain-free walking time or distance. Collectively, results were promising and the procedures were well tolerated by the patients, with few adverse events reported (Figures 2-4). Haemodialysis, diabetes mellitus and complications with coronary arterial disease are all known factors affecting amputation-free survival in patients as these risk factors can negatively affect angiogenesis [10-12]. Matoba et al. postulate that severity of rest pain and number of repeated vascular interventions, in particular bypass procedures may negatively intervene with neo-

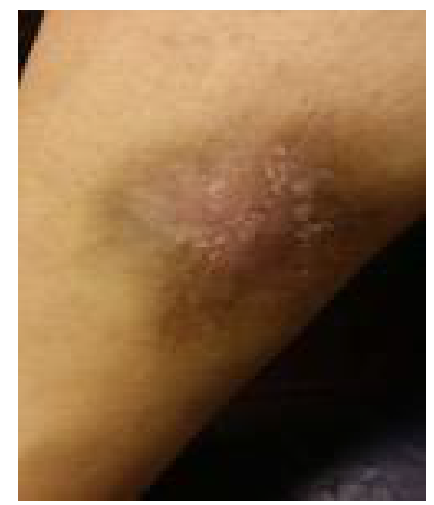

Figure 2J: Patient 17 months post SCT Left shin ulcer.

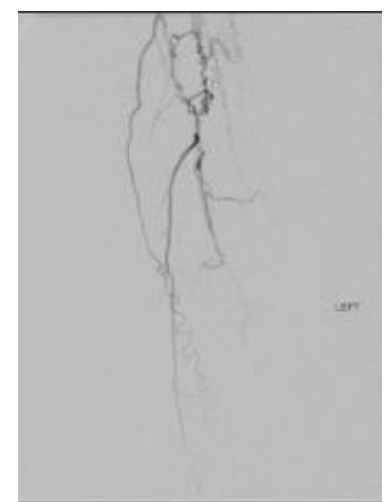

Figure 3A: Patient 1 PRE SCT angiography.

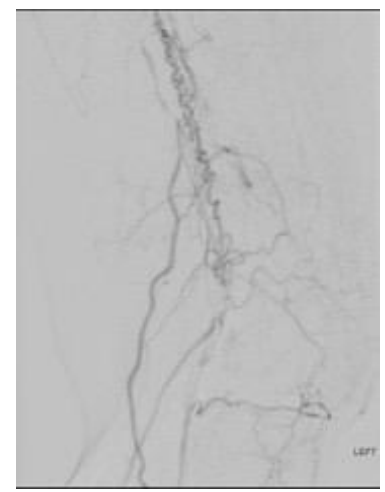

Figure 3B: Patient 13 months Post SCT increased collaterals.

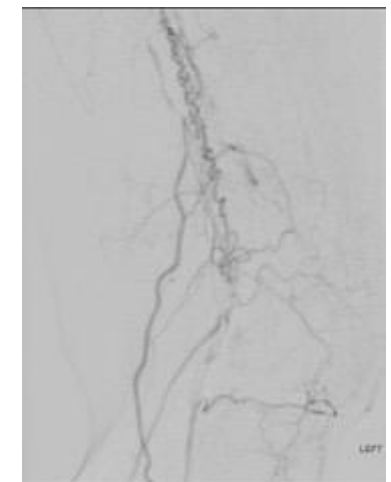

Figure 3C: Patient 1 ATA 3 months Post SCT increased collaterals.

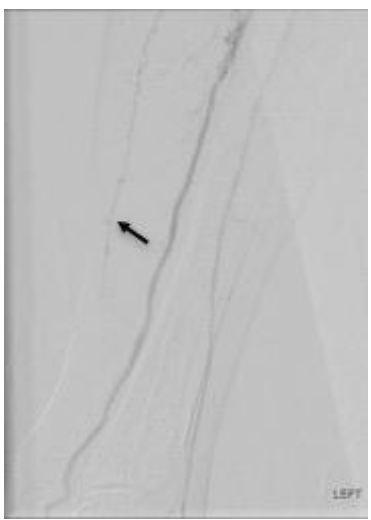

Figure 3D: Patient 13 months POST SCT Hint of new vessel.

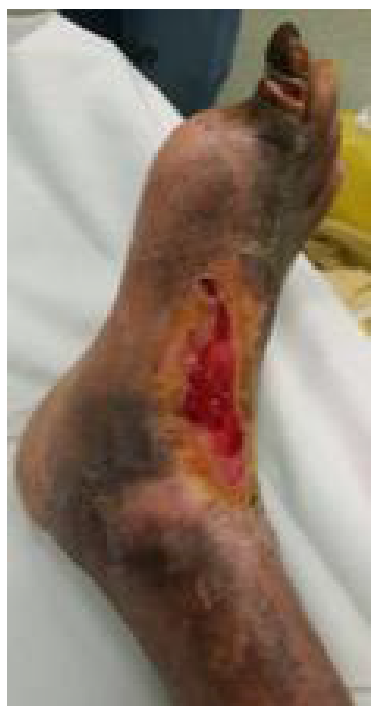

Figure 4A: Patient 2 PRE SCT Right dorsal foot ulcer.

capillary formation sprouting from collateral vessels retarding angiogenesis [13]. While severe rest pain from ischemic limbs may lead to an active production of cytokines promoting angiogenesis, multiple attempts at revascularisation may retard this and render the patient unable to achieve any healing of ischemic wounds. SCT might thus work best through delivery of these angiogenic factors. 
Citation: Peng NNZ, Ting TQ, Yeng BCS (2017) Bone Marrow Stem Cell Therapy (SCT) for Peripheral Arterial Disease (PAD): an Initial Experience. J Blood Lymph 7: 171. doi: 10.4172/2165-7831.1000171

Page 8 of 8

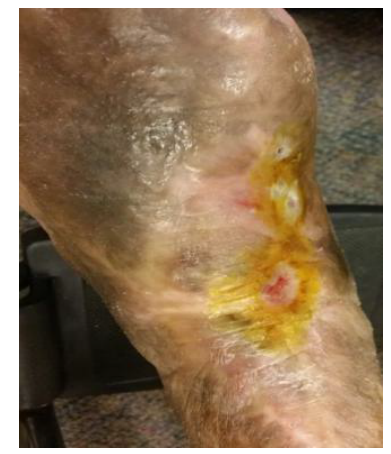

Figure 4B: Patient 22 Months POST SCT Right dorsal foot ulcer.

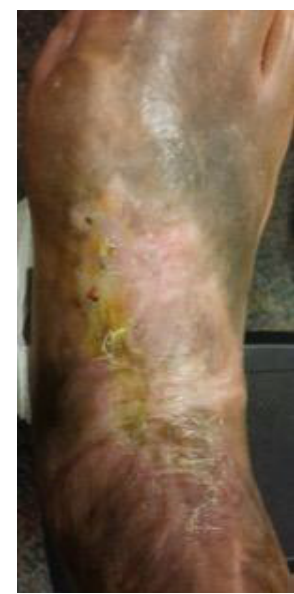

Figure 4C: Patient 23 months POST SCT Right dorsal foot ulcer.

\section{Conclusion}

This study, likely the first of its kind in Singapore and Southeast Asia, has proven no different from others that SCT may eventually provide hope to patients and surgeons that have exhausted conventional treatment options save for amputation(s). The science is not perfect but it remains a potential treatment for chronic limb ischaemia recalcitrant to standard of care techniques. Perhaps more widespread use of SCT can help determine a specific group of patients that will benefit most from it.

\section{References}

1. (2000) Management of peripheral arterial disease (PAD). Transatlantic Inter Society Consensus (TASC). Section D: Chronic critical limb ischemia. Eur J Vasc Endovasc Surg Suppl A: S144-243.

2. Slovut DP, Sullivan TM (2008) Critical limb ischemia: medical and surgical management. Vasc Med 13: 281-291.

3. Ministry of Health, Singapore. National Health Survey 2004. Available at:

4. Dyett JF, Nicholson AA, Ettles DF (2000) Vascular imaging and intervention in peripheral arteries in the diabetic patient. Diabetes Metab Res Rev Suppl 1: S16-S22.

5. Marçola M, Rodrigues CE (2015) Endothelial Progenitor Cells in Tumor Angiogenesis: Another Brick in the Wall. Stem Cells International 2015: 10.

6. Asahara T, Murohara T, Sullivan A, Silver M, van der Zee R, et al. (1997) Isolation of putative progenitor endothelial cells for angiogenesis. Science 275: 964-967.

7. Tateishi-Yuyama, Matsubara H, Murohara T, Ikeda U, Shintani S, et al. (2002) Therapeutic angiogenesis for patients with limb ischaemia by autologous transplantation of bone-marrow cells: a pilot study and a randomised controlled trial. The Lancet 360: 427-435

8. Botti C, Maione C, Coppola A, Sica V, Cobellis G (2012) Autologous bone marrow cell therapy for peripheral arterial disease. Stem Cells and Cloning: Advances and Applications 5: 5-14.

9. Taghavi S, Duran JM, George JC (2011) Stem cell therapy for peripheral arterial disease: a review of clinical trials. Stem Cell Studies 1:e17.

10. Oflaz H, Pusuroglu H, Genchallac H, Demirel S, Bugra Z, et al. (2003) Endothelial function is more impaired in hemodialysis patients than renal transplant recipients. Clin Transplant 17: 528-33.

11. Tamarat R, Silvestre JS, Roussanne SL, Barateau V, Lecomte-Raclet L, et al. (2004) Impairment in ischemia induced neovascularization in diabetes. Am $J$ Pathology 164: 457-66.

12. Heeschen C, Lehmann R, Honold J, Assmus B, Aicher A, et al. (2004) Profoundly reduced neovascularization capacity of bone marrow mononuclear cells derived from patients with chronic ischemic heart disease. Circulation 109: 1615-22.

13. Matoba S, Tatsumi T, Murohara T, Imaizumi T, Katsuda $\mathrm{Y}$, et al. (2008) Long-term clinical outcome after intramuscular implantation of bone marrow mononuclear cells (Therapeutic Angiogenesis by Cell Transplantation [TACT] trial) in patients with chronic limb ischemia. American Heart Journal 156: 10101018. 